\title{
Science skepticism reduced compliance with COVID-19 shelter-in-place policies in the United States
}

\begin{abstract}
Adam Brzezinski ${ }^{1,2}$, Valentin Kecht $\mathbb{D}^{3}$, David Van Dijcke $\mathbb{C}^{4,5}$ and Austin L. Wright $\mathbb{B}^{6}$
Physical distancing reduces transmission risks and slows the spread of COVID-19. Yet compliance with shelter-in-place policies issued by local and regional governments in the United States was uneven and may have been influenced by science skepticism and attitudes towards topics of scientific consensus. Using county-day measures of physical distancing derived from cell phone location data, we demonstrate that the proportion of people who stayed at home after shelter-in-place policies went into effect in March and April 2020 in the United States was significantly lower in counties with a high concentration of science skeptics. These results are robust to controlling for other potential drivers of differential physical distancing, such as political partisanship, income, education and COVID severity. Our findings suggest that public health interventions that take local attitudes towards science into account in their messaging may be more effective.
\end{abstract}

$\mathrm{P}$ hysical distancing reduces interpersonal transmission risks related to the COVID-19 virus ${ }^{1-3}$. Government policies that mandate physical distancing slow the spread of COVID-19 $\left(\right.$ ref. $\left.{ }^{4}\right)$. Local non-compliance with these shelter-in-place orders creates public health risks and may cause regional spread ${ }^{5,6}$. Understanding which local factors impact compliance is a first-order public policy concern and informs evidence-based policy interventions to heighten their efficacy and mitigate the effects of the pandemic.

Recent research highlights several factors that influence compliance: partisanship ${ }^{3,7-12}$, political polarization ${ }^{13}$, poverty and economic dislocation ${ }^{14}$, and differences in risk perception ${ }^{7,15-17}$. These factors also influence physical distancing in the absence of government mandates ${ }^{18}$. Our central contribution is to highlight the role of science skepticism and attitudes regarding topics of scientific consensus in shaping patterns of physical distancing.

We leverage granular, representative data on science skepticism in the United States-beliefs about the anthropogenic (human-made) causes of global warming ${ }^{19}$ - to study how physical distancing patterns vary with skepticism towards science. We combine this county-level science skepticism measure with location trace data on the movement of around 40 million mobile devices as well as data on state-level shelter-in-place policies (sample period, 1 March to 19 April 2020). Our findings suggest that science skepticism is an important determinant of local compliance with government shelter-in-place policies, even after accounting for the role of partisanship, population density, education and income, among other factors. We also benchmark our measure of science skepticism against other measures of belief in science available at the state level, illustrating that our measure captures a more general notion of skepticism towards topics of scientific consensus.

Adapting science-based policy communication to account for the target audience's bias $^{20}$ can mitigate the risk that the message is rejected and the associated policy undermined. This can be achieved by correcting ${ }^{21}$ or pre-emptively debunking ${ }^{22}$ falsely held beliefs about science, thereby countering the dissemination of disinformation through modern media ${ }^{23}$. Taken together, our results underline the importance of tailoring public health interventions and associated messaging campaigns to account for local attitudes towards science.

\section{Results}

Main results. We analyse how physical distancing changes with the imposition of a state-wide shelter-in-place policy. First, we provide descriptive evidence for the role of science skepticism in influencing physical distancing behaviour. Second, we use an event study design with a sample split implemented for counties with high and low degrees of science skepticism. We then complement this approach with a staggered difference-in-differences (DiD) design, where we additionally control for a series of potentially confounding factors.

Figure 1 provides a descriptive view of the data. The left panel depicts the percentage of devices that stayed home each day of the sample period (1 March to 19 April 2020), with polynomial trends fitted for the subsamples of counties above (dark) and below (light) the median belief in anthropogenic global warming. We document a substantial uptick in physical distancing in most counties over the sample period (Fig. 1a) that appears more pronounced in areas with lower levels of science skepticism (dark line). These trends depict a clear difference in physical distancing outcomes between counties with contrasting attitudes towards climate change-a topic of scientific consensus. Figure $1 \mathrm{~b}$ documents the substantial variation in the geographic distribution of such attitudes.

Figure 2a shows the results from the event study approach alongside $95 \%$ confidence intervals (CIs) (sample period, 1 March to 19 April 2020). The coefficients, $t$ statistics and $P$ values are listed in Table 1. Before the introduction of a shelter-in-place mandate, day-to-day changes in physical distancing remain consistently

'Department of Economics, University of Oxford, Oxford, UK. ²Department of Socioeconomics, Vienna University of Economics and Business, Vienna, Austria. ${ }^{3}$ Department of Economics, Bocconi University, Milan, Italy. ${ }^{4}$ Department of Economics, University of Michigan, Ann Arbor, MI, USA. ${ }^{5}$ Institute for New Economic Thinking at the Oxford Martin School, University of Oxford, Oxford, UK. ${ }^{6}$ Harris School of Public Policy, University of Chicago, Chicago, IL, USA. $\otimes_{e}$-mail: dvdijcke@umich.edu 

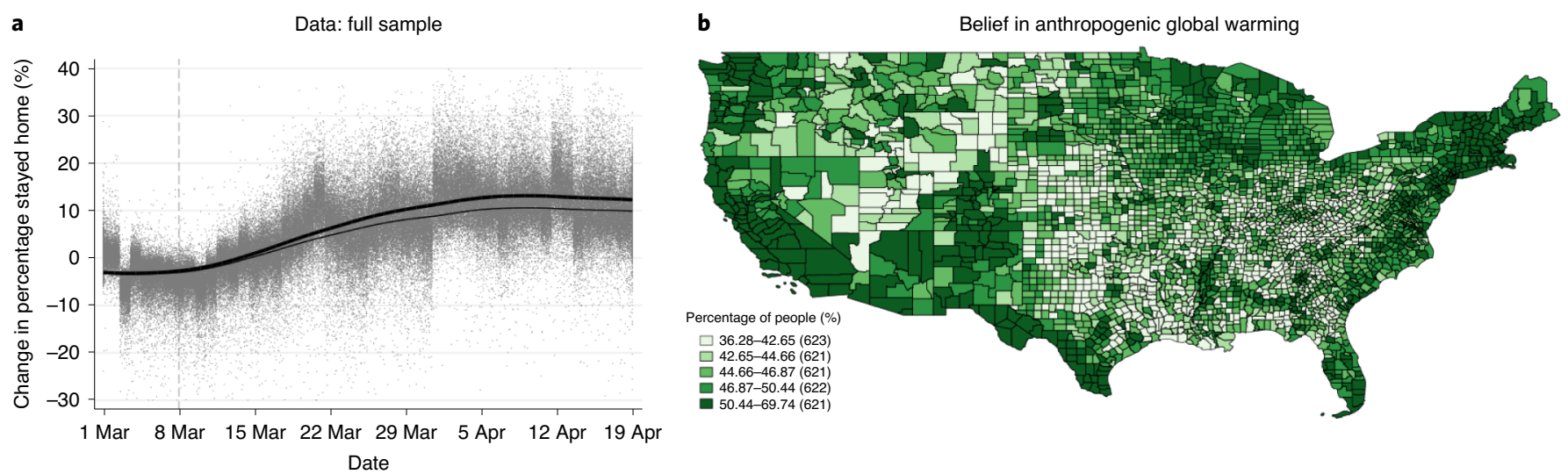

Fig. 1 | Science skepticism and physical distancing: descriptive evidence. a, The light line indicates counties with below-median belief in anthropogenic global warming (skeptic); the dark line indicates those with above-median belief in the same (non-skeptic). The plot shows the percentage difference in devices that stayed home during the sample period (1 March to 19 April) from the day-of-week-specific average during February. The solid lines are from local polynomial smoothing with bandwidth $5 . N=161,363$. b. Percentage of people in each county who believe that global warming is anthropogenic ${ }^{19}$. The source of the shapefile is provided in the Supplementary Information. $N=3,006$. The sample period is from 1 March to 19 April 2020.

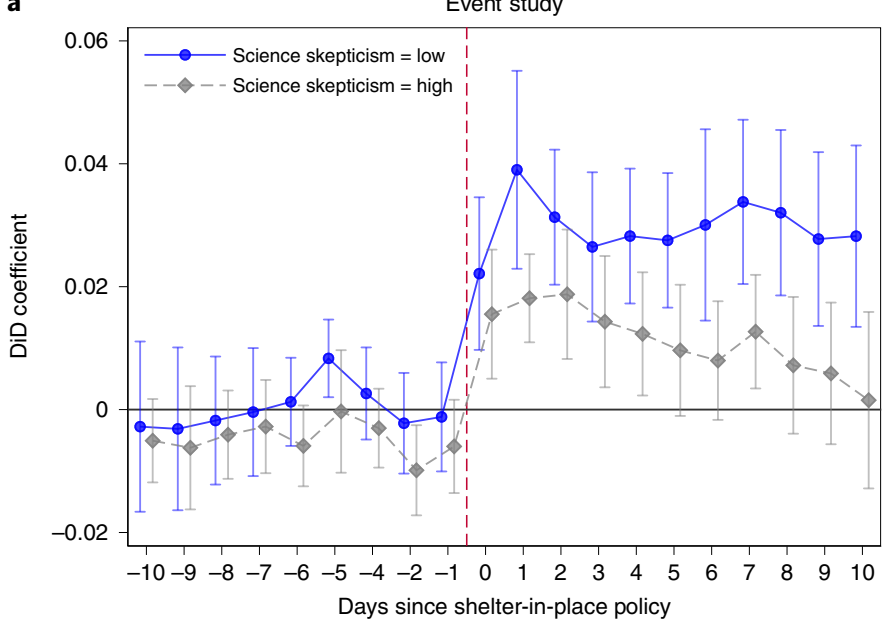

b

$\begin{array}{llll}- \text { Benchmark model } & \diamond+\text { Voting } & \text { +Rural } & \Delta \text { +Education } \\ \times \text { +Income } & + \text { +Religiosity } & \circ \text { +Inst. Health } & \diamond+\text { +Govt Policies } \\ \square+\text { +Local COVID } & \Delta+\text { +State COVID } & + \text { +SiP by COVID } & \diamond+\text { Esst. Workers }\end{array}$

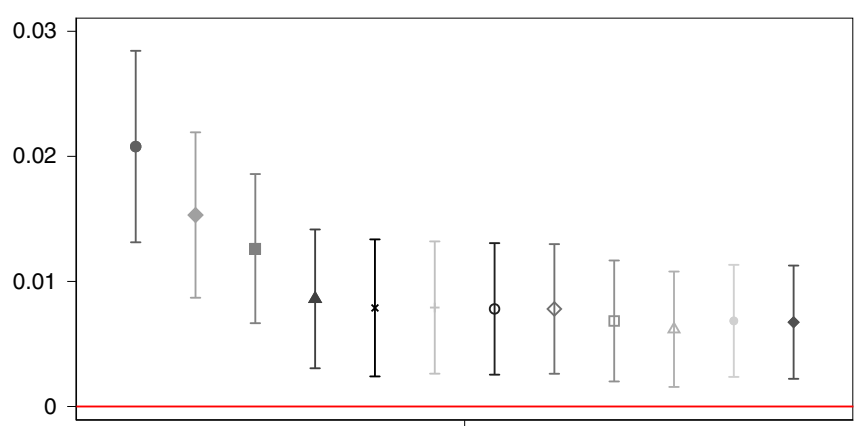

Estimated coefficient: shelter-in-place policy $\times$ science skepticism (low)

Fig. 2 | Compliance with shelter-in-place policy depends on science skepticism. a, DiD estimates with a pre-policy event study approach. The grey line indicates counties with below-median belief in anthropogenic global warming (skeptics); the blue line indicates those with above-median belief in the same (non-skeptics). The sample goes from 15 days before to 10 days after the policy for each county; the effect sizes shown are changes relative to the period 15-11 days and 3 days before the policy. County and date fixed effects are included. $\mathbf{b}$, DiD estimates for the differential effect of a shelter-in-place policy for counties with above-median (non-skeptics) relative to below-median belief in science (skeptics) across different specifications. The point estimates and Cls come from interactions post $s_{s, t} \times \mathrm{BiS}_{c}$ the post-treatment period (post) in state $s$ and a dummy equal to 1 for counties $c$ with above-median belief in science (BiS). 'Benchmark model' controls for date and county fixed effects. The following models progressively expand the benchmark model by introducing the interaction of post ${ }_{s, t}$ with the following variables: '+Voting' includes vote ${ }_{c}$ (equals 1 if $c$ was majority Republican in the 2016 presidential election), '+Rural' includes rural ${ }_{c}$ (equals 1 if $c$ has below-median population density), '+Education' includes educ (equals 1 if $c$ has above-median college education levels), '+Income' includes income ${ }_{c}$ (equals 1 if $c$ has above-median income), '+Religiosity' includes relig (equals 1 if $c$ has above-median levels of religiosity) and '+Inst. Health' includes health ${ }_{c}$ (equals 1 if $c$ has above-median levels of institution health). '+Govt Policies' additionally controls for whether $c$ had a school closure, business closure or state of emergency declaration; '+Local COVID' additionally controls for the number of confirmed COVID cases and deaths in $c_{;}$' + State COVID' additionally controls for the number of confirmed COVID cases and deaths in the state of county c; 'SiP by COVID' adds the interaction of COVID cases and deaths with post $s_{s, t}$ and 'Esst. Workers' adds the interaction of the share of essential workers with post $t_{s, t} . N=87,040$. The sample period was from 1 March to 19 April 2020. In both panels, the dependent variable is the percentage of devices fully at home (see the Supplementary Information for the details). The $95 \% \mathrm{Cls}$ are shown, based on standard errors triple-clustered by county, date and state-week. The regressions employ population weights; for the unweighted results, see Extended Data Fig. 1g,h.

close to zero. Crucially, any slight upward or downward shifts in movement before the onset of a policy are mirrored across high-belief and low-belief counties. Two of the 18 estimated pre-trend dummies are close to but statistically significantly different from 0 (Table 1 ). However, there is no systematic pattern in the p(see Column 4,
Table 1)re-trends, and it is not unexpected to have some false positives when estimating a large number of pre-implementation effects. The parallel evolution of the pre-trends indicates that the difference in effects between the two event studies (high-skepticism and low-skepticism) is consistently estimated. After the first full 
Table 1 | Baseline event-study approach, full results

\begin{tabular}{|c|c|c|c|c|c|c|c|c|}
\hline & \multicolumn{4}{|c|}{ Low science skepticism } & \multicolumn{4}{|c|}{ High science skepticism } \\
\hline & 1 & 2 & 3 & 4 & 5 & 6 & 7 & 8 \\
\hline & Coefficient & $t$ & $P$ & $95 \% \mathrm{Cl}$ & Coefficient & $t$ & $P$ & $95 \% \mathrm{Cl}$ \\
\hline Time -9 & -0.003 & -0.476 & 0.636 & $-0.016,0.010$ & -0.006 & -1.248 & 0.218 & $-0.016,0.004$ \\
\hline Time -8 & -0.002 & -0.344 & 0.732 & $-0.012,0.009$ & -0.004 & -1.143 & 0.259 & $-0.011,0.003$ \\
\hline Time -5 & 0.008 & 2.657 & 0.011 & $0.002,0.015$ & -0.000 & -0.061 & 0.952 & $-0.010,0.010$ \\
\hline Time -4 & 0.003 & 0.705 & 0.485 & $-0.005,0.010$ & -0.003(see Column 4, Table 1) & -0.948 & 0.348 & $-0.009,0.003$ \\
\hline Time -2 & -0.002 & -0.546 & 0.588 & $-0.010,0.006$ & -0.010 & -2.711 & 0.009 & $-0.017,-0.003$ \\
\hline Time -1 & -0.001 & -0.270 & 0.789 & $-0.010,0.008$ & -0.006 & -1.589 & 0.119 & $-0.014,0.002$ \\
\hline Time 4 & 0.028 & 5.182 & $<0.001$ & $0.017,0.039$ & 0.012 & 2.475 & 0.017 & $0.002,0.022$ \\
\hline Time 5 & 0.028 & 5.065 & $<0.001$ & $0.017,0.038$ & 0.010 & 1.820 & 0.075 & $-0.001,0.020$ \\
\hline Time 6 & 0.030 & 3.887 & $<0.001$ & $0.014,0.046$ & 0.008 & 1.664 & 0.103 & $-0.002,0.018$ \\
\hline Time 7 & 0.034 & 5.093 & $<0.001$ & $0.020,0.047$ & 0.013 & 2.763 & 0.008 & $0.003,0.022$ \\
\hline Time 8 & 0.032 & 4.793 & $<0.001$ & $0.019,0.046$ & 0.007 & 1.304 & 0.199 & $-0.004,0.018$ \\
\hline Time 9 & 0.028 & 3.952 & $<0.001$ & $0.014,0.042$ & 0.006 & 1.029 & 0.309 & $-0.006,0.017$ \\
\hline Time 10 & 0.028 & 3.851 & $<0.001$ & $0.013,0.043$ & 0.002 & 0.215 & 0.831 & $-0.013,0.016$ \\
\hline$R^{2}$ & 0.928 & & & & 0.897 & & & \\
\hline d.f. & 42,324 & & & & 42,284 & & & \\
\hline
\end{tabular}

This table corresponds to the results shown in Fig. 2a. The dependent variable is the percentage of devices fully at home. DiD estimates with a pre-policy event study set-up are shown. Columns $1-4$ display the results for the sample restricted to counties with above-median belief in anthropogenic global warming (non-skeptics); columns 5-8 display the results for counties with below-median belief in the same (skeptics). See the Supplementary Information for a more detailed discussion of the event study approach. The sample goes from 15 days before to 10 days after the policy for each county; the effect sizes shown are changes relative to the period 15-11 days, as well as 3 days, before the policy. County and date fixed effects are included. The $95 \%$ Cls are shown, based on standard errors triple-clustered by county, date and state-week. The regressions employ population weights. The sample period is from 1 March to 19 April 2020.

day of a shelter-in-place order, non-skeptic counties see an increase in physical distancing of 3.9 percentage points $\left(b_{\text {non_skeptic }}=0.039\right.$, time 1 coefficient for non-skeptic counties), which is statistically significantly different from zero in a two-tailed test $(t(42,324)=4.88$; $P<0.001 ; b_{\text {non_skeptic }}=0.039 ; 95 \% \mathrm{CI},(0.023,0.055)$; Table 1$)$. Skeptic counties see an increase of 1.8 percentage points $(t(42,284)=5.09$; $P<0.001 ; \quad b_{\text {skeptic }}=0.018 ; 95 \%$ CI, $(0.011,0.025)$; Table 1$)$. These results are robust to alternative specifications, as shown in Extended Data Fig. 1.

We now turn to the staggered DiD approach, which allows us to control for a wide range of possible factors that could confound the relationship between belief in science and physical distancing during the sample period. The results are shown in Fig. 2b. The figure shows, for several different specifications, the point estimates alongside $95 \%$ CIs for the marginal effect of science skepticism-that is, the additional physical distancing response in high-belief relative to low-belief counties. As a benchmark, we start by estimating the same specification as in the event study approach, pooling the post-treatment lags and leaving out further controls except for the day and county fixed effects. This corresponds to the first point estimate in Fig. 2b. The marginal effect of being a non-skeptic county is 2.1 percentage points, which is statistically different from zero according to a two-tailed test $(t(84,692)=5.469$; $P<0.001 ; b_{\text {DiD_benchmark }}=0.021 ; 95 \% \mathrm{CI},(0.013,0.028)$; Table 2$)$ and similar in magnitude to the difference in responses between skeptic and non-skeptic counties in Fig. 2a. To put this in context, the average share of devices staying home on a given day in February 2020 was around $25 \%$ (mean $=0.246$, s.d. $=0.057$, minimum $=0.02$, maximum $=0.667)$, so this constitutes an additional increase for non-skeptic counties of about $9 \%(0.021 / 0.246)$. Considering that a device is counted as staying home only if it is not seen anywhere outside its $153 \mathrm{~m} \times 153 \mathrm{~m}$ designated night-time location on a given day, this is a sizeable difference.

Figure $2 \mathrm{~b}$ also shows the estimates under different sets of control variables, interacted with the post-treatment period, to confirm that the estimated relationship is not driven by confounding factors. One potential concern is that differences in belief in science just serve as a proxy for partisan divides. Supplementary Fig. 1 shows that this is a reasonable concern, as counties that are majority Democrat have a higher fraction of non-skeptics. This partisan gap across parties has also become more polarized over the past decade for a variety of proxies of science skepticism (Supplementary Fig. 2). To account for this potential source of bias, we allow the physical distancing response to a shelter-in-place policy to depend on whether the 2016 Republican vote share exceeded $50 \%$ of the total two-party ballot count (model 2 in Fig. 2b). The marginal effect estimate remains similar at 1.5 percentage points $(t(84,691)=4.663$; $\left.P<0.001 ; b_{\text {DiD_voting }}=0.015 ; 95 \% \mathrm{CI},(0.009,0.022)\right)$ and statistically indistinguishable from the benchmark (Wald test that the coefficient is equal to the benchmark estimate: $F(1,45)=2.78, P=0.102)$. 
Table 2 | DiD approach, full results

\begin{tabular}{|c|c|c|c|c|c|c|c|c|}
\hline \multirow[t]{3}{*}{ 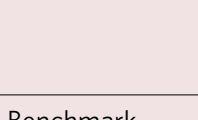 } & \multirow[t]{2}{*}{ Coefficient } & \multirow[t]{2}{*}{$t$} & \multirow[t]{2}{*}{$P$} & \multicolumn{2}{|c|}{$95 \% \mathrm{Cl}$} & \multirow[t]{2}{*}{$R^{2}$} & \multirow[t]{2}{*}{ d.f. } & \multirow[t]{2}{*}{ Obs. } \\
\hline & & & & Lower bound & Upper bound & & & \\
\hline & 0.021 & 5.469 & 0.000 & 0.013 & 0.028 & 0.922 & 84,692 & 87,740 \\
\hline +Rural & 0.013 & 4.264 & 0.000 & 0.007 & 0.019 & 0.923 & 84,690 & 87,740 \\
\hline +Education & 0.009 & 3.123 & 0.003 & 0.003 & 0.014 & 0.924 & 84,689 & 87,740 \\
\hline +Inst. Health & 0.008 & 2.988 & 0.005 & 0.003 & 0.013 & 0.924 & 83,971 & 87,002 \\
\hline +Govt Policies & 0.008 & 3.031 & 0.004 & 0.003 & 0.013 & 0.925 & 83,968 & 87,002 \\
\hline +Local COVID & 0.007 & 2.848 & 0.007 & 0.002 & 0.012 & 0.929 & 83,966 & 87,002 \\
\hline +State COVID & 0.006 & 2.696 & 0.010 & 0.002 & 0.011 & 0.930 & 83,964 & 87,002 \\
\hline +SiP by COVID & 0.007 & 3.078 & 0.004 & 0.002 & 0.011 & 0.931 & 83,960 & 87,002 \\
\hline
\end{tabular}

This table corresponds to the results shown in Fig. $2 b$. The dependent variable is the percentage of devices fully at home. DiD estimates are shown for the differential effect of a shelter-in-place policy for counties with above-median (non-skeptics) relative to below-median belief in science (skeptics) across different specifications. The coefficients refer to the interaction post ${ }_{s, t} \times$ BiS $_{c}$ ' 'Benchmark model' controls for date and county fixed effects. Further models are specified as follows, progressively expanding the benchmark model: ' $+V_{0 \text { oting' }}$ additionally controls for post ${ }_{s, t} \times$ vote $_{c}$, where vote ${ }_{c}=1$ if $c$ was majority Republican in the 2016 presidential election; ' + Rural' additionally controls for post $\times$ rural $_{c}$, where rural $=1$ if $c$ has below-median population density; ' + Education' additionally controls for

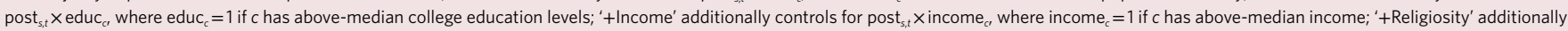
controls for post $t_{s, t} \times$ relig $_{c}$, where relig $g_{c}=1$ if $c$ has above-median levels of religiosity; ' + Inst. Health' additionally controls for post ${ }_{s, t} \times$ health $_{c}$, where health ${ }_{c}=1$ if $c$ has above-median levels of institution health; '+Govt. Policies' additionally controls for whether c had a school closure, business closure or state of emergency declaration; '+Local COVID' additionally controls for the number of confirmed COVID cases and deaths in $c_{;}$' + State COVID' additionally controls for the number of confirmed COVID cases and deaths in the state of county c; 'SiP by COVID' additionally controls for the interaction of COVID cases and deaths with post $s_{s, t}$ and 'Essential Workers' further controls for the interaction of the share of essential workers with post $t_{s, t}$. The standard errors are triple-clustered by county, date and state-week. The regressions employ population weights. The sample period is from 1 March to 19 April 2020.

Thus, even after partialling out the differential effects due to partisanship, there is a significantly higher response to the shelter-in-place policy in non-skeptic counties.

We consider several other potential sources of bias by sequentially adding further (interacted) control variables, and we show the coefficient sizes, $t$ statistics and $P$ values in Table 2 . Across these specifications, we account for how rural (model 3), educated (model 4), wealthy (model 5), religious (model 6) and institutionally robust (model 7) a county is by interacting these variables with the shelter-in-place policy dummy. This approach allows the estimated effect of shelter-in-place policies to vary with all these additional factors. We also consider whether related business or school closure policies have been introduced (model 8 ), the local severity of COVID-19 cases and deaths (model 9), and state-wide cases and deaths (model 10). In model 11, we additionally allow the effect of local and state-wide COVID-19 cases and deaths on physical distancing to vary with the introduction of the shelter-in-place policy. Finally, in model 12, we also control for the proportion of essential workers in a county, again interacted with the shelter-in-place policy. This helps mitigate the potential confounding factor that some people may leave their homes because their work demands it rather than because they do not comply with the shelter-in-place policy.

Even though several of these measures, especially religiosity, income and education, may over-control for variation in the outcome of interest (that is, these covariates are colliders), the estimate remains robust and statistically significant, even in the fully saturated model that includes the complete set of interacted control variables (the last model in Table 2). The robustness of the point estimates supports the idea that the patterns of non-compliance will probably also hold for alternative measures of science skepticism, as we further explore in the discussion section.

Robustness. In the Supplementary Information, we investigate several potential concerns with our approach. We begin by demonstrating the robustness of the main results to a number of alternative sampling and model specifications. We introduce these results in Extended Data Fig. 1. In Extended Data Fig. 1a,b, we demonstrate that the main results hold if we leverage a longer pre-sample window of ten days. The use of the ten-day window means that the number of days used as a baseline period balances the number of leads and lags. In Extended Data Fig. 1c, we estimate the main event study without an omitted treatment lead. In Extended Data Fig. 1d, we estimate the main specification with a saturated set of covariates-by-date fixed effects. In Extended Data Fig. 1e,f, we use a one-day pre-sample window. This means that the number of omitted treatment leads (one) matches the number of omitted pre-window dates. Extended Data Fig. 1g,h replicates the main event study and DiD models without weighting the units by population. In each of these additional variants, we observe a similar pattern of results: parallel pre-trends in physical distancing across high-belief and low-belief counties, large increases in physical distancing among high-belief counties after the introduction of a shelter-in-place policy, and robust and statistically significant marginal effects of belief in science after accounting for the battery of potential confounders discussed earlier (partisanship, rurality, education, income, religiosity, institutional health, related government policies, and local and state-wide COVID-19 severity).

Construct validity. We next consider the construct validity of our measure of belief in science. It is possible that attitudes towards the anthropogenic causes of climate change are bundled together with a range of other ideological considerations, especially partisanship ${ }^{24}$. We assess how our measure of science skepticism relates to other measures of attitudes towards science, scientific inquiry and scientific breakthroughs.

To confirm that our measure of skepticism about the human causes of global warming proxies more general attitudes towards topics of scientific consensus, we test to what extent it correlates with other measures of belief in science. As an initial benchmark, we use the Pew American Values Survey, pooled over the years 2002-2009. The sample period has the advantage that it precedes the pronounced increase from 2008 onwards in both climate change 

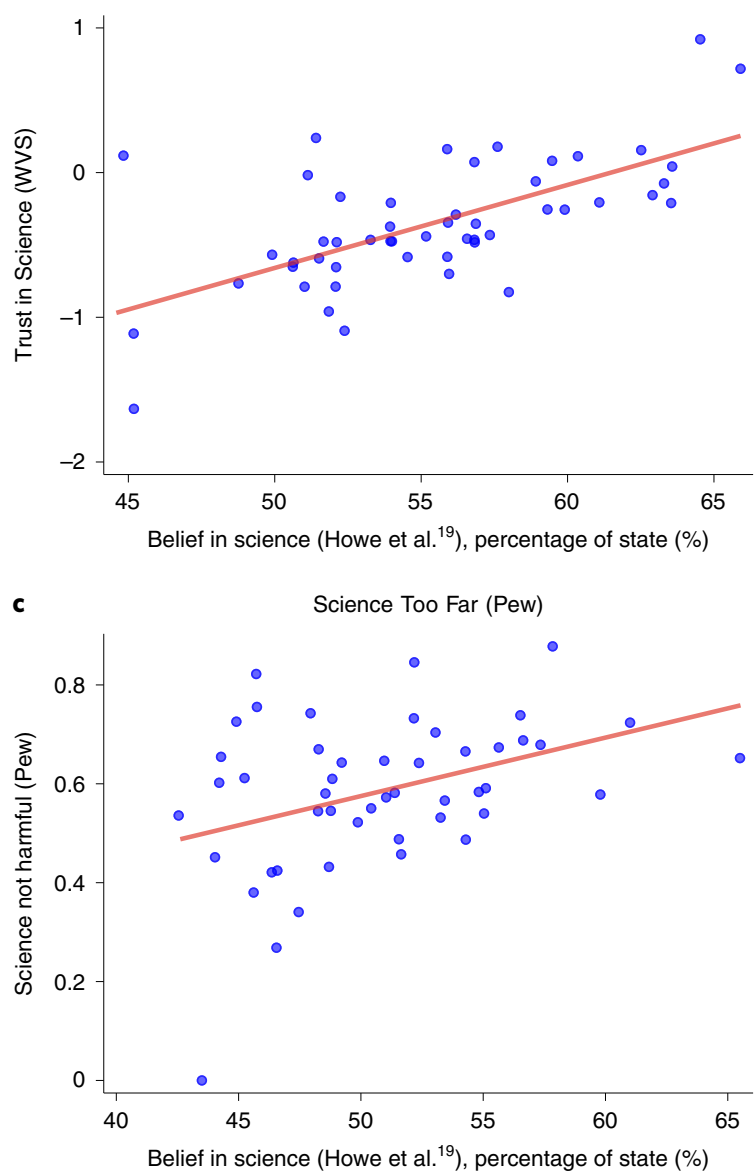

b
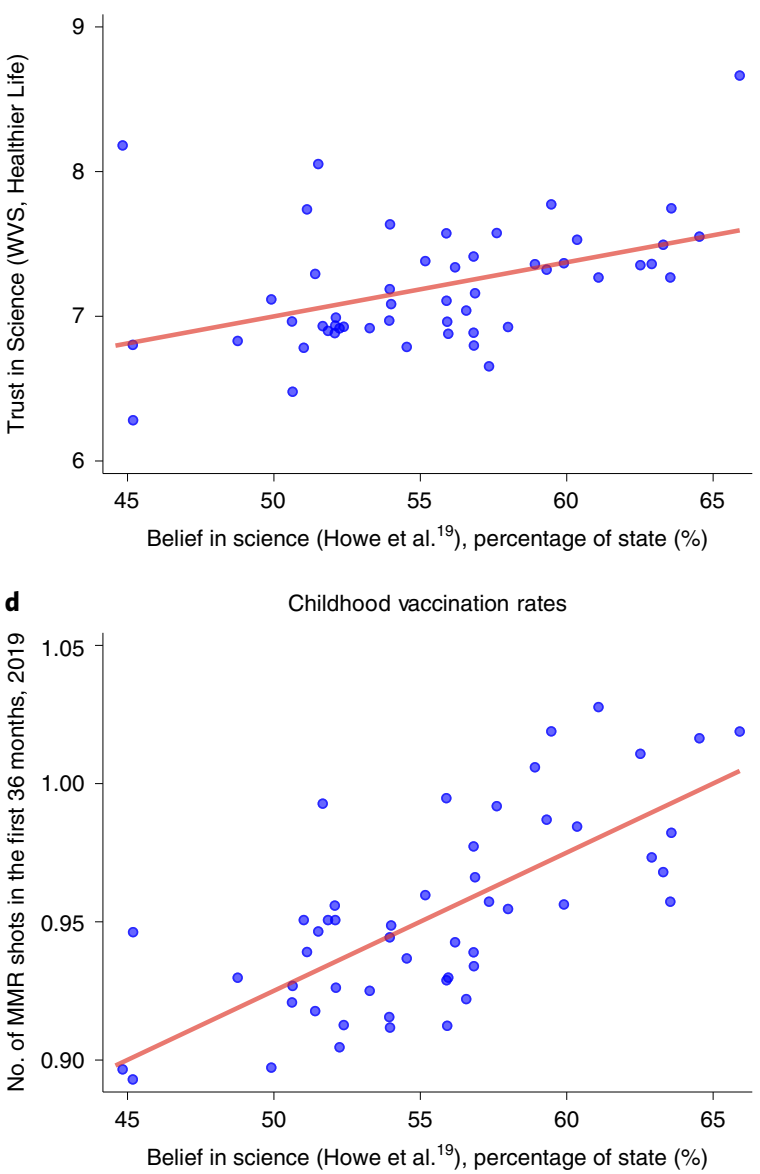

Fig. 3 | Benchmarking science skepticism (main specification) with alternative measures of trust in science. a-c, Scatter plots of the baseline proxy for belief in science from ref. ${ }^{19}$, aggregated to the state level using population weights, against various alternative measures. Higher values of belief in science correspond to weaker skepticism. 'Trust in Science (WVS)' is the first polychoric principal component of six variables measuring attitudes towards science from the WVS (2011 and 2017 waves pooled). All variables were standardized, survey-weighted and averaged at the state level. PCA, principal component analysis. 'Trust in Science (WVS), Healthier Life' indicates the level of agreement with the statement 'Science and technology are making our lives healthier, easier, and more comfortable'. Higher values indicate higher levels of trust in science. See Supplementary Table 1 for more details. 'Science Too Far (Pew)' indicates the proportion of the state sample population in Pew Research Center's American Values Survey (2002-2009) reporting disagreement with the statement 'I am worried that science is going too far and is hurting society rather than helping it'. $\mathbf{d}$, Using state-level vaccination rates to benchmark our baseline proxy for science skepticism. The childhood vaccination rate is the average number of MMR vaccination shots received by children during the first 36 months of their lives at the state level.

skepticism ${ }^{25,26}$ (driven by partisan polarization) and polarization in attitudes towards science, which we document in Supplementary Fig. 2. We supplement this data source with information from the World Values Survey (WVS). The data are pooled over two waves (2011 and 2017) and report average levels of trust in science at the state level. The latter is determined as the first polychoric principal component of six questions concerning beliefs on science and technology. We also leverage data on the average state-level number of MMR vaccinations received by children at the age of 36 months. The use of MMR vaccinations in this age group has been found to reflect broader vaccine hesitancy ${ }^{27,28}$.

We visualize the relationship between these alternative measures of attitudes towards science in Fig. 3. Figure 3a,b presents the principal component from the WVS (trust in science) and healthier life factor loading, respectively. Notice the robust, positive relation. In Fig. 3c, we illustrate the association between the Pew American Values Survey measure and the measure in ref. ${ }^{19}$. In Fig. $3 \mathrm{~d}$, we introduce the scatter plot of MMR vaccination rates and beliefs on global warming. We find similarly consistent positive associations.
In Supplementary Table 1, we introduce regression-based estimates. The estimated associations are large, ranging from $0.331\left(R^{2}=0.11\right.$, WVS factor loading for 'science is important for daily life') to 0.635 $\left(R^{2}=0.4\right.$, WVS principal component analysis). These results suggest that our primary measure of belief in science is a representative measure of the more general public attitude towards science.

Science skepticism, mask use and vaccine hesitancy. Although our analysis focuses primarily on physical distancing, the role of science skepticism in public health policy is much broader, potentially influencing other mitigating behaviours such as mask use and vaccine hesitancy. Science skepticism may undermine public mask use and reinforce hesitancy, thwarting attempts to establish herd immunity. To explore these additional policy-relevant issues, we gather data on county-level mask use and vaccine hesitancy across the United States. In Fig. 4, we show that the correlation between science skepticism and mask use at the height of the pandemic in the United States (July 2020) is negative (strong skepticism negatively associated with mask use) and robust to accounting for local 
a

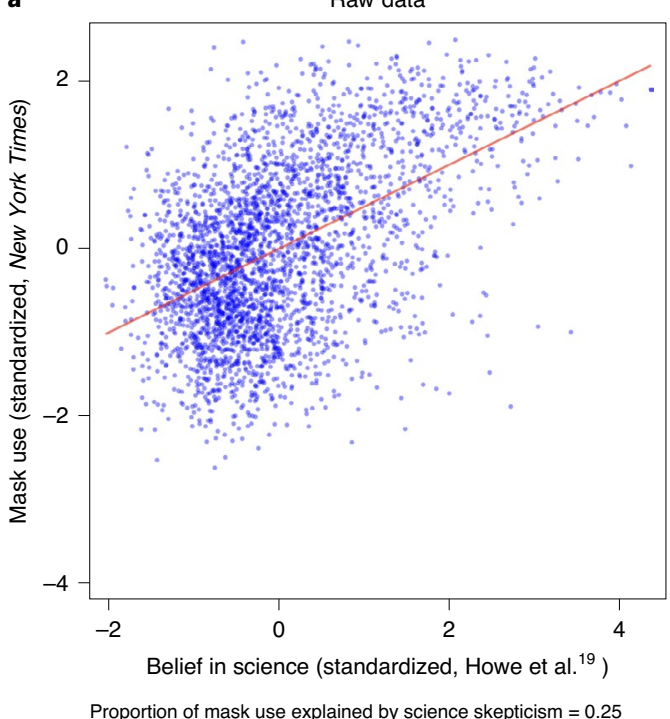

b

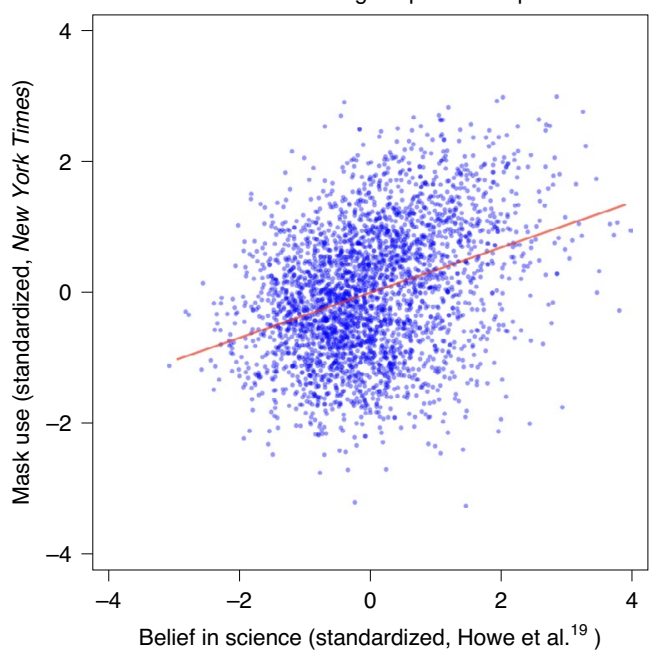

Proportion of mask use explained by science skepticism $=0.12$ (after residualizing county partisanship)

Fig. 4 | Correlation with mask use (county level). a, Scatter plot of belief in science (from ref. ${ }^{19}$ ) against county-level mask use in July 2020. Higher values of belief in science correspond to weaker skepticism. Mask use is defined as the share of people that stated they always wear a mask, which is then standardized to have a mean of zero and a standard deviation of one. These data were obtained from a large-scale survey commissioned by the New York Times, which was conducted online between 2 July and 14 July and includes 250,000 survey responses. For details on the data, see ref. ${ }^{60}$. b, Same as in a, but showing residuals from regressions on an indicator of a county's partisanship. Each county is classified according to which party had a higher vote share than the other party in the 2016 presidential election.

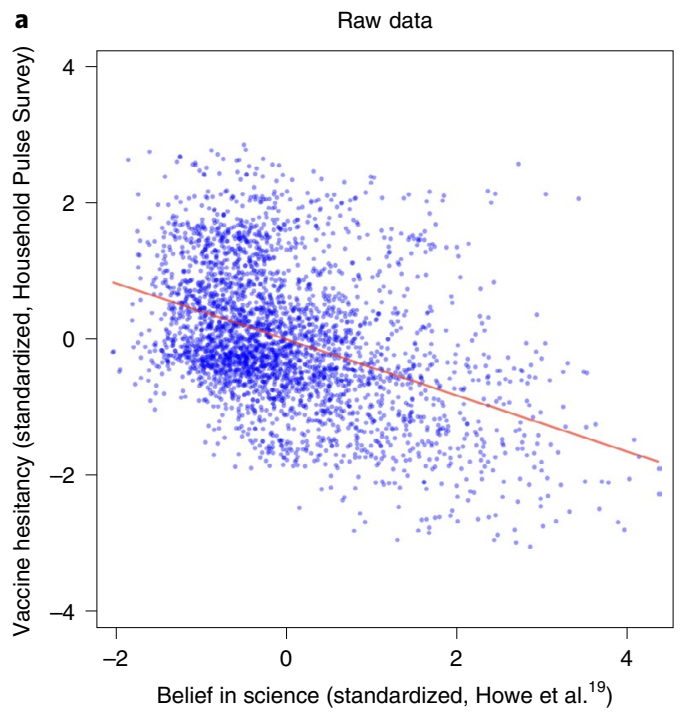

Proportion of vaccine hesitancy explained by science skepticism $=0.17$

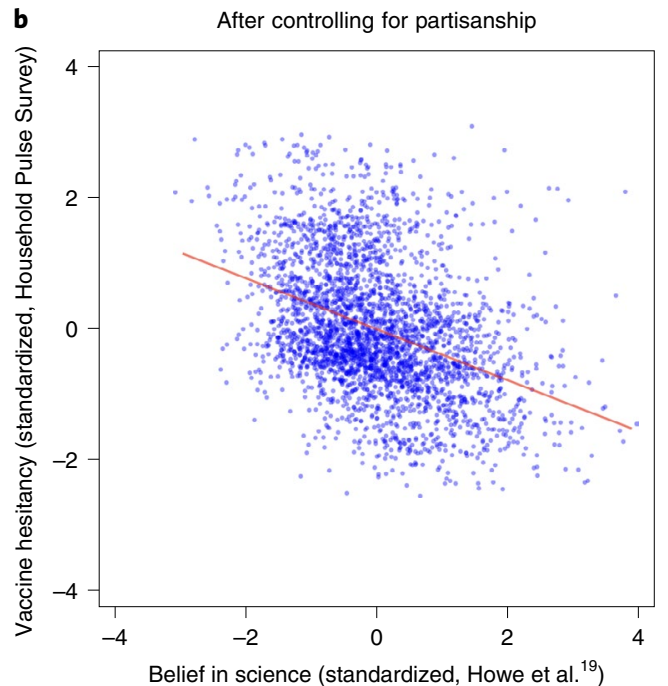

Proportion of vaccine hesitancy explained by science skepticism $=0.15$ (after residualizing county partisanship)

Fig. 5 | Correlation with vaccine hesitancy (county level). a, Scatter plot of belief in science (from ref. ${ }^{19}$ ) against county-level vaccine hesitancy in April 2021. Higher values of belief in science correspond to weaker skepticism. Hesitancy is measured as the share of county residents with little or no interest in receiving a COVID-19 vaccine, which is then standardized to have a mean of zero and a standard deviation of one. These data were obtained from the county-level estimates provided by the US Census Bureau, leveraging their Household Pulse Survey. For additional information, see https://bit.ly/3osf1M5. b. Same as in a, but showing residuals from regressions on an indicator of a county's partisanship. Each county is classified according to which party had a higher vote share than the other party in the 2016 presidential election.

partisanship, the primary confounding factor of concern in our main analysis. In Fig. 5, we replicate this analysis for vaccine hesitancy in April 2021. We find a similarly striking pattern, with science skepticism and local hesitancy being positively correlated (strong skepticism positively associated with hesitancy), which is robust to conditioning out the role of partisanship, an especially poignant concern in light of recent evidence that hesitancy is disproportionately high among polled Republicans. Although data limitations restrict an investigation of the role of mask use and hesitancy that is comparable to our main estimates, these findings suggest a persistent effect of belief in science on public health measures beyond physical distancing. 


\section{Discussion}

Our main result suggests that counties with lower levels of skepticism about topics of scientific consensus (non-skeptics) have complied with shelter-in-place mandates at a higher rate than counties with higher levels of science skepticism (skeptics). We argue that this is because skeptics are less likely to accept the motivations underlying science-based public policies.

When a policy has imperfect enforcement, compliance will be incomplete among people who believe that the policy has no beneficial or harm-reducing effects. In the case of the COVID-19 pandemic, estimates of such effects hinged crucially on scientific assessments and medical research that indicated the virus spread through interpersonal contact and could be mitigated by physical distancing (see ref. ${ }^{29}$ for an early review of this literature). Moreover, in the United States, policy enforcement was indeed imperfect ${ }^{30,31}$. As a result, the success of shelter-in-place policies in combating the spread of the virus necessarily relied for a large part on voluntary compliance ${ }^{32-34}$. In areas where scientific skepticism is widespread, we hypothesize that fewer people would believe in the benefits of social distancing, reducing policy effectiveness.

Science skepticism can influence potentially costly social behaviours through several plausible mechanisms. Skepticism may reduce the willingness of individuals to engage with scientific information that contradicts their prior beliefs ${ }^{26}$. Skeptics may also engage in less information-seeking behaviour, preferring to rely on anecdotal or common-sense assessments of the risks they or their community face. Furthermore, skeptics may specifically seek out slanted coverage that reinforces their existing beliefs or biases. In any of these cases, subsequent risk perceptions will remain unchanged by new information or will conform to existing assessments of potential threats ${ }^{35}$. Research on science communication during the COVID-19 pandemic provides ample evidence of these mechanisms. One study finds that experimental subjects with lower cognitive reflection and scientific knowledge were more willing to share fake or false stories about the pandemic ${ }^{36}$. In another paper, survey respondents were more likely to believe that COVID-19 risks were exaggerated and that the virus was purposefully manufactured and spread if they had a psychological predisposition to reject expert assessments and engage in conspiratorial thinking ${ }^{37}$. Merkley and Loewen ${ }^{38}$ provide evidence that anti-intellectualismwhich is closely related to what we describe as science skepticism-is linked to diminished concern regarding COVID-19, perceptions of risk factors and willingness to engage with and seek out information from experts. Finally, Gitmez et al. ${ }^{39}$ introduce a theoretical model whereby information seeking is slanted, leading skeptics to seek out media coverage that minimizes the reported threat posed by non-compliance with shelter-in-place mandates. These studies provide an empirical and theoretical foundation for our core hypothesis.

There remain important unresolved questions about the psychological, political and social origins of science skepticism. It is possible that skepticism emerges due to a real or perceived challenge to an existing set of beliefs or principles ('identity-protective cognition' $)^{40}$. These beliefs may be informed by misconceptions about causal relationships ${ }^{41}$ or motivated by political affiliations ${ }^{42}$, exposure to slanted sources of information ${ }^{43,44}$, conspiracy theories ${ }^{26}$ or related cultural mythologies ${ }^{45}$. An individual's principles may be ideological heuristics that are challenged by scientific inquiry, triggering psychological reactance and, as a consequence, a rejection of scientific expertise ${ }^{46,47}$. Political and social institutions may also emerge to reinforce these dynamics. Rekker ${ }^{48}$ provides a review of these dynamics, noting that skepticism may lead to the rejection of either a narrow set of scientific facts or scientific expertise as an entire epistemic system. Indeed, the drivers of science skepticism have been shown to be more heterogeneous than previously thought, with political partisanship being an important predictor of climate skepticism ${ }^{40,49,50}$, while religiosity better predicts vaccine and evolution skepticism ${ }^{51,52}$.
Supplementary Fig. 1 illustrates that political partisanship is indeed related to science skepticism using our county-level measure of climate change skepticism from ref. ${ }^{19}$, while Supplementary Fig. 2 documents an across-the-board increase in political polarization around science attitudes over the past decade in the United States. Kahan ${ }^{24}$ provides a psychological explanation for self-reported climate skepticism as being rooted in individuals' cultural or political ties rather than their cognitive capacity. Taken together, it is clear that a robust exploration of science skepticism through the lens of climate dynamics (our primary measure) requires a careful consideration of the cultural and political systems within which this skepticism is embedded. These systems include partisanship, religiosity, rurality and urbanicity, and educational attainment. We account for these factors empirically to address important concerns about the construct validity of our measure-whether the patterns of non-compliance we observe are likely to hold for alternative measures of science skepticism. Our findings complement recent research that finds COVID-19 skepticism to have similar antecedents as vaccine and climate skepticism ${ }^{53}$.

By documenting how science skepticism can undermine public health interventions, our research complements earlier experimental and survey-based results on the drivers of such skepticism and affirms their importance ${ }^{36-38}$. Our findings suggest that it would benefit the effective implementation of public policies to tailor public messaging to correct or pre-empt falsely held beliefs about the scientific evidence these policies are based on ${ }^{20,23}$. The science communication literature offers many potential strategies to achieve these goals ${ }^{54}$. Similarly, science institutions can attempt to pre-empt skeptical reception of and non-compliance with science-based policy by 'pre-bunking' ${ }^{22}$ false beliefs about science and promoting education and scientific literacy training ${ }^{55}$. Such 'psychological inoculation ${ }^{56}$ has been applied with some success in the context of vaccination ${ }^{57}$ and climate change ${ }^{58}$. We contribute to this body of research by documenting that substantial behavioural harm can arise when science skepticism undermines compliance with public policy.

Our study has several limitations. Although we present credible evidence that movement patterns followed parallel trends prior to shelter-in-place policies, these interventions are not strictly exogenous. These orders also entered into effect early during the pandemic, and our analysis focuses on compliance during this initial phase of the crisis in the United States. Social distancing over the course of the pandemic and the potential role of so-called pandemic fatigue may be of interest to future work ${ }^{59}$ but are not examined in this study. Furthermore, while we introduce measures of mask use and vaccine hesitancy observed later in the pandemic, current mask use and vaccine utilization may be driven by other factors that we do not fully explore here. We also anticipate that future research could meaningfully contribute to our understanding of scientific skepticism by gathering less polarized measures of understanding of and beliefs in scientific concepts and facts than climate skepticism.

\section{Methods}

Data. We analyse differential changes in county-level movement patterns and physical distancing after the implementation of shelter-in-place policies in the United States (see the Supplementary Information for more detail). Daily panel data are aggregated to the county level from GPS pings of more than 40 million mobile devices, obtained from SafeGraph (https://www.safegraph.com), a data company that aggregates anonymized location data from numerous applications to provide insights about physical places, via the PlaceKey Community (https:// www.placekey.io). These data allow us to track the percentage of devices that stayed home all day. The latter is defined as the ratio of the number of devices that were not seen outside of their home all day in a given county over the total number of devices observed in the county that day. A device's home is determined as the common night-time location (delineated by a $153 \mathrm{~m} \times 153 \mathrm{~m}$ geo-fence) over a six-week period. The underlying anonymized data were subjected to exhaustive data processing with the aim to guarantee reliability, granularity, anonymity and 
accuracy. The panel of devices in the sample is designed to be geographically and demographically representative, with a $97 \%$ correlation between the panel's population density and the US Census's population density at the county level.

To mitigate the spread of COVID-19, county and state governments implemented shelter-in-place policies during the second half of March 2020. We collect the implementation dates of state- and county-level school and business closures, state-of-emergency declarations and shelter-in-place policies from various sources. When a policy goes into effect after 12:00 on a given day, we assign it an implementation date one day later. We measure science skepticism using data assembled by Howe et al. ${ }^{19}$ at the county level. Our main measure is the estimated percentage of people who agree with the statement that global warming is caused by humans. Despite scientific consensus that humans are the primary cause of present and projected climate change dynamics, there is substantial variability in local beliefs about this topic in the United States. We leverage this variation to study how patterns of physical distancing differ across counties with lower levels of science skepticism (higher belief in science).

Research design. We adopt two related empirical approaches to analyse how physical distancing behaviour depends on whether a county exhibits above- or below-median levels of science skepticism (see the Supplementary Information for more detail). First, we implement a county-day-level event study design where we focus on the impact of shelter-in-place policies on physical distancing, in line with related studies ${ }^{8,14,18}$. We estimate the response separately for counties with above-median and below-median levels of science skepticism. The event study design checks for the presence of pre-treatment (anticipation) effects. The main effects will be consistently estimated even if there is some evidence of anticipation effects as long as those anticipation effects are parallel across the two event studies. An additional benefit of the event study design is that it allows us to estimate and visualize how the policy response changes dynamically after the introduction of shelter-in-place mandates.

Second, we use a staggered DiD approach to estimate the differential response to shelter-in-place policies for counties with above-median versus below-median science skepticism. The split-sample event study is a powerful approach when stratifying over one dimension with a well-balanced binary classification. This is the case with the event study design we use for our measure of science skepticism. However, the introduction of additional dimensions requires stratification over all of them simultaneously. With a large number of potential confounding factors, the split-sample event study design is statistically underpowered. To address the fact that there is probably a range of potential sources of bias (as noted in the Discussion), we adopt a staggered DiD design. This approach is closely aligned with the event study approach but includes a single dummy that is equal to one at or after the implementation date, which is interacted with a dummy for whether the county is marked by above- or below-median belief in science. Moreover, we interact a vector of potential confounders with the treatment indicator, enabling us to control for the effect of additional covariates on the physical distancing response to a shelter-in-place policy. One primary control variable is local partisanship, which is correlated with science skepticism (Supplementary Fig. 1). Political polarization with respect to climate change and attitudes towards science generally in the United States have been amplified over the past decade (Supplementary Fig. 2). We attempt to address this concern by partialling out any marginal effects associated with partisanship, using voting records from the 2016 presidential election. The effect of science skepticism may also be confounded by how rural, educated, religious and wealthy a given community is. Institutional health, the share of essential workers, and local and regional exposure to COVID-19 may similarly influence our primary estimates. We incorporate these additional controls as well.

For each of the two approaches, we weigh each county by its population within the regression framework to provide representative results. In Extended Data Fig. 1, we show that the main results are robust to estimating each design without population weights and varying baseline periods.

Reporting Summary. Further information on research design is available in the Nature Research Reporting Summary linked to this article.

\section{Data availability}

The mobility data provided by SafeGraph are proprietary but available to academic researchers via https://www.safegraph.com. Source data are provided with this paper. All other data that support the findings of this study are available at https:// www.openicpsr.org/openicpsr/project/144861.

\section{Code availability}

The code for all analyses in this study can be found at https://github.com/ Davidvandijcke/science_skepticism_nature_hb.

Received: 24 May 2020; Accepted: 27 September 2021; Published online: 13 October 2021

\section{References}

1. Viner, R. M. et al. School closure and management practices during coronavirus outbreaks including COVID-19: a rapid systematic review. Lancet Child Adolesc. Health 5, 397-404 (2020).

2. Anderson, R. M., Heesterbeek, H., Klinkenberg, D. \& Hollingsworth, T. D. How will country-based mitigation measures influence the course of the COVID-19 epidemic? Lancet 395, 931-934 (2020).

3. Bai, Y. et al. Presumed asymptomatic carrier transmission of COVID-19. JAMA https://doi.org/10.1001/jama.2020.2565 (2020).

4. Hsiang, S. et al. The effect of large-scale anti-contagion policies on the COVID-19 pandemic. Nature 584, 262-267 (2020).

5. Lewnard, J. A. \& Lo, N. C. Scientific and ethical basis for social-distancing interventions against COVID-19. Lancet Infect. Dis. 20, 631-633 (2020).

6. Chen, S., Yang, J., Yang, W., Wang, C. \& Bärnighausen, T. COVID-19 control in China during mass population movements at new year. Lancet 395 , 764-766 (2020)

7. Allcott, H. et al. Polarization and Public Health: Partisan Differences in Social Distancing during the Coronavirus Pandemic Working Paper No. 26946 (NBER, 2020); 10.3386/w26946

8. Painter, M. \& Qiu, T. Political beliefs affect compliance with government mandates. J. Econ. Behav. Organ. 185, 688-701 (2021).

9. Grossman, G., Kim, S., Rexer, J. M. \& Thirumurthy, H. Political partisanship influences behavioral responses to governors' recommendations for COVID-19 prevention in the United States. Proc. Natl Acad. Sci. USA 117, 24144-24153 (2020)

10. Gadarian, S. K., Goodman, S. W. \& Pepinsky, T. B. Partisanship, health behavior, and policy attitudes in the early stages of the COVID-19 pandemic. PLoS ONE 16, e0249596 (2021).

11. Gollwitzer, A. et al. Partisan differences in physical distancing are linked to health outcomes during the COVID-19 pandemic. Nat. Hum. Behav. 4, 1186-1197 (2020).

12. Clinton, J., Cohen, J., Lapinski, J. \& Trussler, M. Partisan pandemic: how partisanship and public health concerns affect individuals' social mobility during COVID-19. Sci. Adv. 7, eabd7204 (2021).

13. Cornelson, K. \& Miloucheva, B. Political Polarization, Social Fragmentation and Cooperation during a Pandemic Working Paper No. 663 (University of Toronto Department of Economics, 2020); https://www.economics.utoronto. ca/public/workingPapers/tecipa-663.pdf

14. Wright, A. L., Sonin, K., Driscoll, J. \& Wilson, J. Poverty and economic dislocation reduce compliance with COVID-19 shelter-in-place protocols. J. Econ. Behav. Organ. 180, 544-554 (2020).

15. Akesson, J., Ashworth-Hayes, S., Hahn, R., Metcalfe, R. D. \& Rasooly, I. Fatalism, Beliefs, and Behaviors during the COVID-19 Pandemic Working Paper No. 27245 (NBER, 2020); https://doi.org/10.3386/w27245

16. Barrios, J. M. \& Hochberg, Y. V. Risk Perception through the Lens of Politics in the Time of the COVID-19 Pandemic Working Paper No. 27008 (NBER, 2020); https://doi.org/10.3386/w27008

17. Engle, S., Stromme, J. \& Zhou, A. Staying at home: mobility effects of COVID-19. Preprint at SSRN https://doi.org/10.2139/ssrn.3565703 (2020).

18. Brzezinski, A., Deiana, G., Kecht, V. \& Van Dijcke, D. The COVID-19 Pandemic: Government vs. Community Action across the United States Working Paper No. 2020-06 (INET Oxford, 2020).

19. Howe, P., Mildenberger, M., Marlon, J. \& Leiserowitz, A. Geographic variation in opinions on climate change at state and local scales in the USA. Nat. Clim. Change 5, 596-603 (2015).

20. Jamieson, K. H. \& Hardy, B. W. Leveraging scientific credibility about Arctic sea ice trends in a polarized political environment. Proc. Natl Acad. Sci. USA 111, 13598-13605 (2014).

21. Carey, J. M., Chi, V., Flynn, D., Nyhan, B. \& Zeitzoff, T. The effects of corrective information about disease epidemics and outbreaks: evidence from Zika and yellow fever in Brazil. Sci. Adv. 6, eaaw7449 (2020).

22. Roozenbeek, J., Van Der Linden, S. \& Nygren, T. Prebunking interventions based on 'inoculation' theory can reduce susceptibility to misinformation across cultures. Harvard Kennedy School Misinformation Review https://doi. org/10.37016//mr-2020-008 (2020).

23. Iyengar, S. \& Massey, D. S. Scientific communication in a post-truth society. Proc. Natl Acad. Sci. USA 116, 7656-7661 (2019).

24. Kahan, D. M. Climate-science communication and the measurement problem. Polit. Psychol. 36, 1-43 (2015).

25. Merkley, E. \& Stecula, D. A. Party cues in the news: Democratic elites, Republican backlash, and the dynamics of climate skepticism. Br. J. Polit. Sci. https://doi.org/10.1017/S0007123420000113 (2020).

26. Lewandowsky, S., Gignac, G. E. \& Oberauer, K. The role of conspiracist ideation and worldviews in predicting rejection of science. PLOS ONE $\mathbf{8}$, e75637 (2013)

27. The Lancet Child Adolescent Health. Vaccine hesitancy: a generation at risk. Lancet Child Adolesc. Health 3, 281 (2019).

28. Torracinta, L., Tanner, R. \& Vanderslott, S. MMR vaccine attitude and uptake research in the United Kingdom: a critical review. Vaccines 9, 402 (2021). 
29. Chu, D. K. et al. Physical distancing, face masks, and eye protection to prevent person-to-person transmission of SARS-CoV-2 and COVID-19: a systematic review and meta-analysis. Lancet 395, 1973-1987 (2020).

30. Gostin, L. \& Wetter, S. Why there's no national lockdown. The Atlantic https://www.theatlantic.com/ideas/archive/2020/03/why-theres-no-nationallockdown/609127/ (2020).

31. Rusch, K. \& Smith, C. How do you enforce a law that tramples the land of the free? New York Times https://www.nytimes.com/2020/05/11/us/ coronavirus-california-lockdowns.html (2020).

32. Brzezinski, A., Kecht, V. \& Van Dijcke, D. The Cost of Staying Open: Voluntary Social Distancing and Lockdowns in the US Working Paper No. 910 (University of Oxford, Department of Economics, 2020); https://doi.org/ $10.2139 /$ ssrn. 3614494

33. Gupta, S., Simon, K. \& Wing, C. Mandated and voluntary social distancing during the COVID-19 epidemic. Brookings Pap. Econ. Act. 2020, 269-326 (2020).

34. Barrios, J. M., Benmelech, E., Hochberg, Y. V., Sapienza, P. \& Zingales, L. Civic capital and social distancing during the COVID-19 pandemic. J. Public Econ. https://doi.org/10.1016/j.jpubeco.2020.104310 (2021).

35. Jolley, D. \& Douglas, K. M. The effects of anti-vaccine conspiracy theories on vaccination intentions. PLoS ONE 9, e89177 (2014).

36. Pennycook, G., McPhetres, J., Zhang, Y., Lu, J. G. \& Rand, D. G. Fighting COVID-19 misinformation on social media: experimental evidence for a scalable accuracy-nudge intervention. Psychol. Sci. 31, 770-780 (2020).

37. Uscinski, J. E. et al. Why do people believe COVID-19 conspiracy theories? Harvard Kennedy School Misinformation Review (2020); https://doi. org/10.37016/mr-2020-015

38. Merkley, E. \& Loewen, P. J. Anti-intellectualism and the mass public's response to the COVID-19 pandemic. Nat. Hum. Behav. 5, 706-715 (2021)

39. Gitmez, A., Sonin, K. \& Wright, A. L. Political Economy of Crisis Response Working Paper No. 2020-68 (University of Chicago, Becker Friedman Institute for Economics, 2020); https://doi.org/10.2139/SSRN.3604320

40. McPhetres, J., Bago, B. \& Pennycook, G. Science beliefs, political ideology, and cognitive sophistication. Preprint at OSF https://doi.org/10.31219/ osf.io/ad9v7 (2021).

41. Whitson, J. A. \& Galinsky, A. D. Lacking control increases illusory pattern perception. Science 322, 115-117 (2008).

42. Blank, J. M. \& Shaw, D. Does partisanship shape attitudes toward science and public policy? The case for ideology and religion. Ann. Am. Acad. Polit. Soc. Sci. 658, 18-35 (2015).

43. Scheufele, D. A. \& Krause, N. M. Science audiences, misinformation, and fake news. Proc. Natl Acad. Sci. USA 116, $7662-7669$ (2019)

44. Nisbet, M. C. et al. Knowledge, reservations, or promise? A media effects model for public perceptions of science and technology. Commun. Res. 29, 584-608 (2002).

45. Oliver, J. E. \& Wood, T. J. Conspiracy theories and the paranoid style(s) of mass opinion. Am. J. Polit. Sci. 58, 952-966 (2014).

46. Nisbet, E. C., Cooper, K. E. \& Garrett, R. K. The partisan brain: how dissonant science messages lead conservatives and liberals to (dis) trust science. Ann. Am. Acad. Polit. Soc. Sci. 658, 36-66 (2015).

47. Ma, Y., Dixon, G. \& Hmielowski, J. D. Psychological reactance from reading basic facts on climate change: the role of prior views and political identification. Environ. Commun. 13, 71-86 (2019)

48. Rekker, R. The nature and origins of political polarization over science. Public Underst. Sci. 30, 352-368 (2021).

49. Hornsey, M. J., Harris, E. A. \& Fielding, K. S. Relationships among conspiratorial beliefs, conservatism and climate scepticism across nations. Nat. Clim. Change 8, 614-620 (2018).

50. Rutjens, B. T., Heine, S. J., Sutton, R. M. \& van Harreveld, F. in Advances in Experimental Social Psychology Vol. 57 (ed. Olson, J. M.) 125-165 (Elsevier, 2018); https://doi.org/10.1016/bs.aesp.2017.08.001
51. Rutjens, B. T. \& van der Lee, R. Spiritual skepticism? Heterogeneous science skepticism in the Netherlands. Public Underst. Sci. 29, 335-352 (2020).

52. Rutjens, B. T. et al. Science skepticism across 24 countries. Soc. Psychol. Personal. Sci. https://doi.org/10.1177/19485506211001329 (2021).

53. Rutjens, B. T., van der Linden, S. \& van der Lee, R. Science skepticism in times of COVID-19. Group Process. Intergroup Relat. 24, 276-283 (2021).

54. Fischhoff, B. The sciences of science communication. Proc. Natl Acad. Sci. USA 110, 14033-14039 (2013).

55. McPhetres, J., Rutjens, B. T., Weinstein, N. \& Brisson, J. A. Modifying attitudes about modified foods: increased knowledge leads to more positive attitudes. J. Environ. Psychol. 64, 21-29 (2019).

56. McGuire, W. J. Inducing resistance to persuasion. Some contemporary approaches. in Self and Society: An Anthology of Readings (eds. Haaland, C. C. \& Kaelber, W. O.) 192-230 (Ginn Custom Publishing, 1964); https://doi.org/ 10.1016/S0065-2601(08)60052-0

57. Jolley, D. \& Douglas, K. M. Prevention is better than cure: addressing anti-vaccine conspiracy theories. J. Appl. Soc. Psychol. 47, 459-469 (2017).

58. Van der Linden, S., Leiserowitz, A., Rosenthal, S. \& Maibach, E. Inoculating the public against misinformation about climate change. Glob. Chall. 1, 1600008 (2017).

59. Michie, S., West, R. \& Harvey, N. The concept of 'fatigue' in tackling COVID-19. BMJ https://doi.org/10.1136/bmj.m4171 (2020).

60. Milosh, M., Painter, M., Van Dijcke, D. \& Wright, A. L. Unmasking Partisanship: How Polarization Influences Public Responses to Collective Risk Working Paper No. 2020-102 (University of Chicago, Becker Friedman Institute for Economics, 2020); https://doi.org/10.2139/ssrn.3664779

\section{Acknowledgements}

We thank SafeGraph for providing their data and support. We also thank R. Van der Ploeg, C. Samii and K. Cem Ketenci for support and discussions, and B. Baitan for excellent research assistance. The authors received no specific funding for this work

\section{Author contributions}

All authors conceived the idea. V.K., D.V.D. and A.L.W. provided and prepared the data. All authors developed the baseline model. A.B., D.V.D. and A.L.W. completed the robustness checks. V.K. and A.L.W. constructed the descriptive figures and performed the analyses on construct validity. A.B. and A.L.W. drafted the manuscript. D.V.D. and V.K. provided critical revisions. All authors approved the final version of the manuscript for submission.

\section{Competing interests}

The authors declare no competing interests.

\section{Additional information}

Extended data is available for this paper at https://doi.org/10.1038/s41562-021-01227-0. Supplementary information The online version contains supplementary material available at https://doi.org/10.1038/s41562-021-01227-0.

Correspondence and requests for materials should be addressed to David Van Dijcke. Peer review information Nature Human Behaviour thanks Toby Bolsen, James Druckman and Jonathan Jay for their contribution to the peer review of this work. Peer reviewer reports are available.

Reprints and permissions information is available at www.nature.com/reprints.

Publisher's note Springer Nature remains neutral with regard to jurisdictional claims in published maps and institutional affiliations.

(c) The Author(s), under exclusive licence to Springer Nature Limited 2021 
(a) Event Study (10 day baseline)

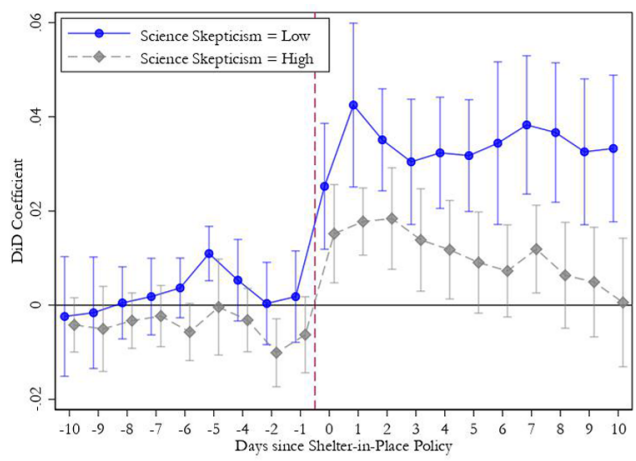

(c) Event Study (all leads)

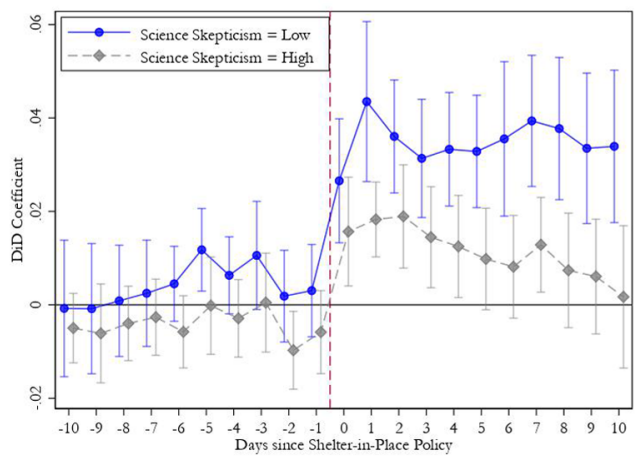

(e) Event Study (1 Day baseline)

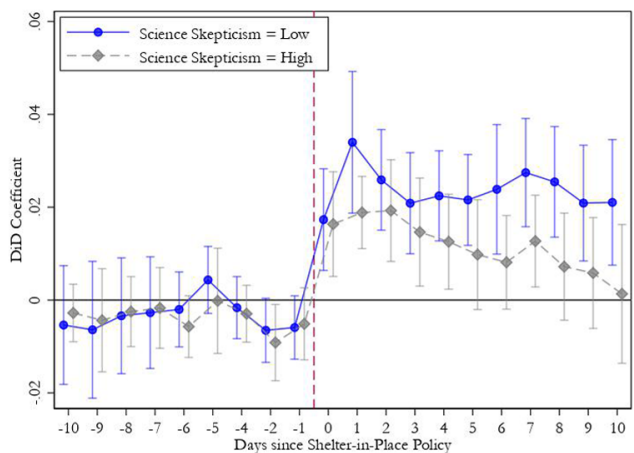

(g) Event Study (unweighted)

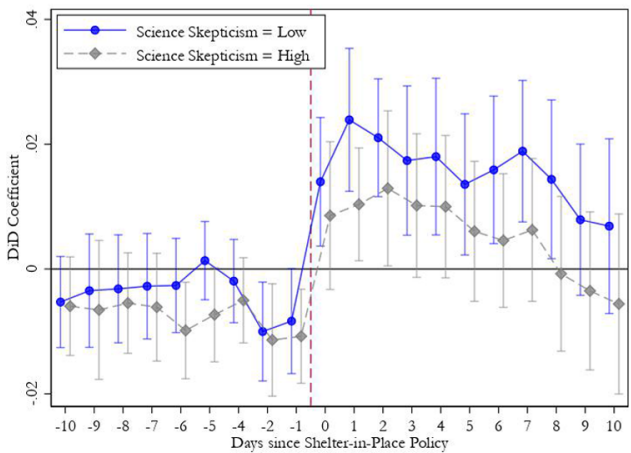

(b) Diff.-In-Diff. (10 day baseline)

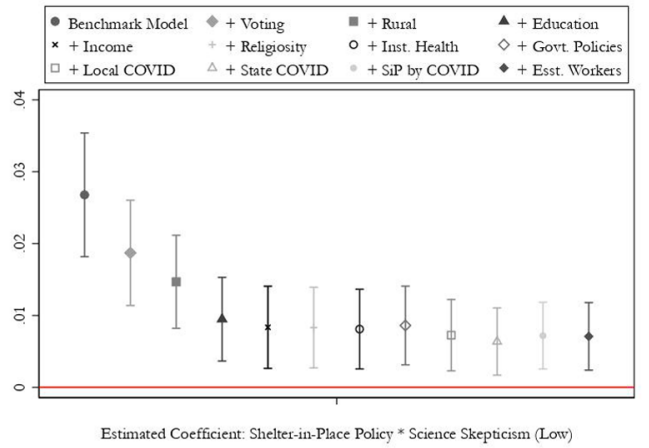

(d) Diff.-In-Diff. (saturated fixed effects)

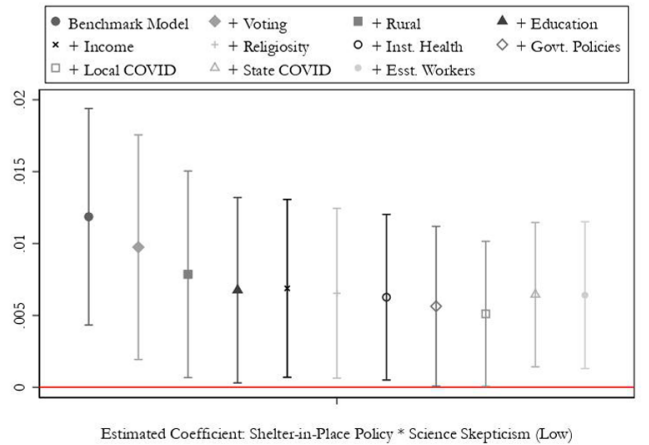

(f) Difference-In-Difference (1 Day baseline)

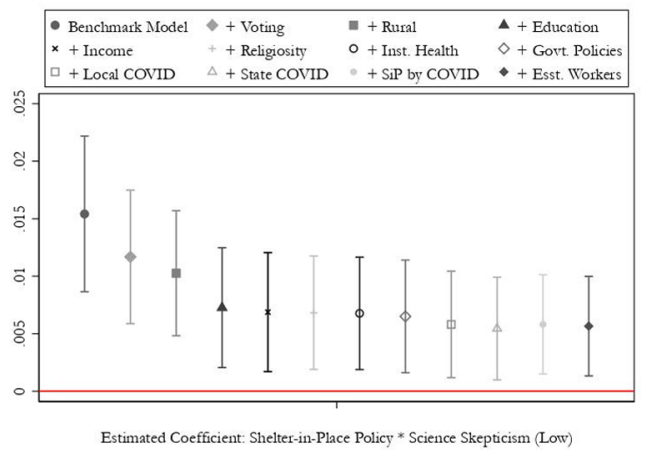

(h) Difference-In-Difference (unweighted)

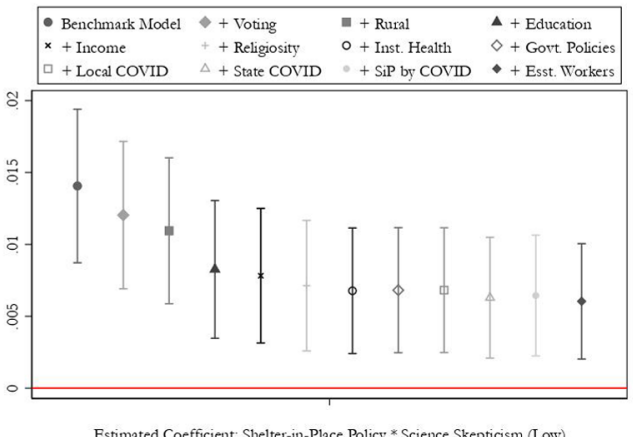

Estimated Coefficient- Shelter-in-Place Policy * Science Skepticism (Low) 
Extended Data Fig. 1 | Compliance With Shelter-in-Place Policy (Additional Results). Panel a)-h): The specifications are the same as in the corresponding panels in Fig. 2, except: panels a) and b) use a 10 day baseline period (rather than five); panel c) includes all leads in the event study specification; panel d) includes saturated covariates $x$ date fixed effects; panels e) and f) use an alternative one day baseline period (rather than five); panel g) and $h$ ) are not population weighted. Sample period: March 1 to April 19 2020. See Fig. 2 for additional details. 


\section{nature portfolio}

Corresponding author(s): David van Dijcke

Last updated by author(s): Aug 25, 2021

\section{Reporting Summary}

Nature Portfolio wishes to improve the reproducibility of the work that we publish. This form provides structure for consistency and transparency in reporting. For further information on Nature Portfolio policies, see our Editorial Policies and the Editorial Policy Checklist.

\section{Statistics}

For all statistical analyses, confirm that the following items are present in the figure legend, table legend, main text, or Methods section.

n/a Confirmed

$\square$ The exact sample size $(n)$ for each experimental group/condition, given as a discrete number and unit of measurement

$\square$ A statement on whether measurements were taken from distinct samples or whether the same sample was measured repeatedly

$\square$ The statistical test(s) used AND whether they are one- or two-sided

Only common tests should be described solely by name; describe more complex techniques in the Methods section.

$\bigotimes$ A description of all covariates tested

$\square$ \ A description of any assumptions or corrections, such as tests of normality and adjustment for multiple comparisons

$\triangle$ A full description of the statistical parameters including central tendency (e.g. means) or other basic estimates (e.g. regression coefficient)

$\triangle$ AND variation (e.g. standard deviation) or associated estimates of uncertainty (e.g. confidence intervals)

$\varnothing$ For null hypothesis testing, the test statistic (e.g. $F, t, r$ ) with confidence intervals, effect sizes, degrees of freedom and $P$ value noted Give $P$ values as exact values whenever suitable.

Х $\square$ For Bayesian analysis, information on the choice of priors and Markov chain Monte Carlo settings

Х $\square$ For hierarchical and complex designs, identification of the appropriate level for tests and full reporting of outcomes

Х $\square$ Estimates of effect sizes (e.g. Cohen's $d$, Pearson's $r$ ), indicating how they were calculated

Our web collection on statistics for biologists contains articles on many of the points above.

\section{Software and code}

Policy information about availability of computer code

Data collection Data on social distancing have been collected by SafeGraph. All other data have been drawn from public accessible sources.

Data analysis Data preparation: R; data analysis and visualization: STATA 16

For manuscripts utilizing custom algorithms or software that are central to the research but not yet described in published literature, software must be made available to editors and reviewers. We strongly encourage code deposition in a community repository (e.g. GitHub). See the Nature Portfolio guidelines for submitting code \& software for further information.

\section{Data}

Policy information about availability of data

All manuscripts must include a data availability statement. This statement should provide the following information, where applicable:

- Accession codes, unique identifiers, or web links for publicly available datasets

- A description of any restrictions on data availability

- For clinical datasets or third party data, please ensure that the statement adheres to our policy

Data availability statement The mobility data provided by SafeGraph are proprietary but available to academic researchers via https://www.safegraph.com. All other data that support the findings of this study are available at https://www.openicpsr.org/openicpsr/project/144861. 


\section{Field-specific reporting}

Please select the one below that is the best fit for your research. If you are not sure, read the appropriate sections before making your selection.
Life sciences
Вehavioural \& social sciences
Ecological, evolutionary \& environmental sciences

For a reference copy of the document with all sections, see nature.com/documents/nr-reporting-summary-flat.pdf

\section{Behavioural \& social sciences study design}

All studies must disclose on these points even when the disclosure is negative.

Study description

Econometric analysis of observational data

Research sample

SafeGraph's dataset is based on an underlying panel of mobile devices in nearly all 200,000+ Census Block Groups (CBG) in the United States. Only CBGs with less than 5 devices are excluded to preserve privacy. The sample is representative along several dimensions: First, geographic bias of the data is small, with the absolute difference between the panel's density and the true population density according to the US census remaining below $1 \%$ for all counties in the sample; the correlation between both measures is 0.97 . Second, the data is similarly representative at the county level in terms of race, demographic and income groups.

Sampling strategy

The sample size was determined by SafeGraph rather than us. However, as the dataset is based on up to 40 million devices, we are confident that the data provide an appropriate proxy of the actual degree of social distancing in a CBG. We further aggregate the data to the county level to merge the covariates of interest. This leaves us with a panel of more than 3000 counties per day.

Data collection

The data are based on location trace data obtained by tracking GPS pings from up to 40 million devices across the United States

Timing

Daily social distancing data are provided by SafeGraph from 1 February 2020 onwards. For the baseline specification, the sample runs from 15 days before to 10 days after the implementation of a state-level shelter-in-place policy. This implies a sample ranging from 4 March and 18 April 2020.

Data exclusions

We drop those counties from the sample that moved ahead of their state in implementing shelter-in-place policies. This is primarily done to counter concerns that the timing of local policy adoption is endogenous to local virus severity and physical distancing patterns (counties moving ahead of states in implementing a local shelter-in-place).

Non-participation N/A

Randomization

\section{Reporting for specific materials, systems and methods}

We require information from authors about some types of materials, experimental systems and methods used in many studies. Here, indicate whether each material, system or method listed is relevant to your study. If you are not sure if a list item applies to your research, read the appropriate section before selecting a response.

\begin{tabular}{|c|c|}
\hline$n / a$ & Involved in the study \\
\hline$\bigotimes$ & $\square$ Antibodies \\
\hline$\bigotimes$ & $\square$ Eukaryotic cell lines \\
\hline$\bigotimes$ & $\square$ Palaeontology and archaeology \\
\hline$\bigotimes$ & $\square$ Animals and other organisms \\
\hline Х & $\square$ Human research participants \\
\hline$\bigotimes$ & $\square$ Clinical data \\
\hline$\bigotimes$ & $\square$ Dual use research of concern \\
\hline
\end{tabular}

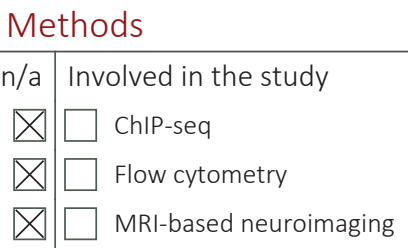

